\title{
RES effects in Italian Wholesale Electricity Market
}

\author{
Angelica Gianfreda \\ Energy Markets Group \\ Department of Management Science and Operations \\ London Business School \\ Email: agianfreda@london.edu
}

\author{
Lucia Parisio \\ Dipartimento di Economia, Metodi quantitativi \\ e Strategie d'impresa \\ University Milano-Bicocca \\ Email: lucia.parisio@unimib.it
}

\begin{abstract}
We empirically analyze the relationship between wholesale electricity day-ahead and regulation prices in the presence of high share of RES generation. Our results only partly confirm those obtained by Skytte (1999) for the Oslo area. In the Italian case, regulating power prices follow spot prices and, in some cases, they are two or three times larger than the latter ones. We generally observe that the amount of regulation does not affect regulating power prices, even if they actually behave differently to up- and down-regulation. In addition, we find empirical evidence of very high premia for readiness with different behaviors according to Italian zones.
\end{abstract}

\section{INTRODUCTION}

We aim at investigating the effect of RES generation on Italian wholesale prices, looking at both the spot and regulation markets. We refer to Skytte (1999) since he firstly proposed the analysis of these prices and the regulation power in the area of Oslo, in Norway. The analysis of markets for regulation power is becoming more and more interesting given the high RES penetration into EU markets. Specifically, we consider the Italian market, IPEX, where the intermittent generation has substantially increased over the last two years. Indeed, we study the dynamics of prices from 2012 to end of 2014 looking at the Italian physical zones ${ }^{1}$ where most of renewable generation is placed; namely in North, where hydro is predominant, South and Sicily, where most of wind and photovoltaic generation is placed. After selecting the most interesting hours, hence looking at intra-daily profiles for load, wind and solar generation, we determine the relationship between spot and regulation prices, providing implications on the premia for readiness occurring into Italian zones. The paper is structured as follows: Section II describes the structure of the Italian market, with respect to spot and regulation markets; the evolution of RES in Italy is analyzed into Section III, the model under investigation is explained in Section IV. Data and preliminary analysis are presented in Section $\mathrm{V}$, the empirical results are in Section VI, and finally Section VII concludes.

\section{THE STRUCTURE OF THE ITALIAN ELECTRICITY WHOLESALE MARKET}

The Italian wholesale electricity market began to operate on April 2004. For the whole year 2004 bids were allowed for

\footnotetext{
${ }^{1}$ An interested reader can find a precise description of the Italian market structure in [4].
}

suppliers only while demand bids were submitted by a publicly owned operator (Acquirente Unico) which was in charge of procuring electricity for the whole retail market. From 2005 onwards bidding on the demand side was allowed for eligible consumers and through time the eligibility threshold was lowered until the full opening of the market. The Italian wholesale market soon attracted a great portion of demand and supply and it showed a liquidity rate of $72 \%$ in 2013, with 207 TWh over a total of 289 TWh exchanged in the organized wholesale market. The Italian market is managed by an independent system operator named Gestore dei Mercati Energetici, GME. The exchange of electricity is organized in a spot and a forward market. In this paper we focus on the spot markets, and in particular on the relationship emerging from the various sessions that take place from the day-ahead through the real time. In the day-ahead market (MGP), participants submit offers/bids where they specify the quantity and the minimum/maximum price at which they are willing to sell/purchase electricity. The MGP for delivery at date $T$ opens on day $T-9$ and closes at 9:15 a.m. on day $T-1$. Bids/offers submitted are accepted under the economic meritorder criterion and take into account transmission capacity limits between zones. The equilibrium price is determined, for each hour, by the intersection of the demand and supply curves and it happens to be different from zone to zone when transmission capacity limits are saturated. The accepted demand bids pertaining to consuming units belonging to Italian geographical zones are valued at a single national price, which is equal to the average of the prices of geographical zones, weighted for the quantities purchased in these zones. Suppliers receive the equilibrium price prevailing in the zone where they sell electricity, which coincides with the system marginal price when Italy is a unique market and market splitting does not occur. The intra-day market allows market participants to modify the schedules defined in the day-ahead MGP, by submitting additional supply offers or demand bids. It takes place in four sessions: MI1 and MI2 open at 10:45 and close at 12.30 and 14.40 , respectively, on day $T-1$; MI3 and MI4, introduced in 2010, open at 16.00 on day $T-1$ but close respectively at 7.30 and 11.45 on day $T$. Unlike in the MGP, demand bids accepted on the intra-day markets are valued at the zonal price. Both MGP and MI are managed by the GME. Instead, the transmission system operator, Terna, manages the ancillary services market, which 
is organized into two sessions: an "ex-ante" MSD (as the Italian name Mercato dei Servizi di Dispacciamento) and a balancing market MB. The ex-ante MSD and the MB take place in multiple sessions, as specified in the dispatching rules $^{2}$. In addition, the participation on MGP and MI markets is voluntary, whereas the participation on MSD and MB is compulsory. The number of market participants on MGP was 143 in 2012, 154 in 2013, and 208 in 2014; on MSD was 25 in 2012, 27 in 2013 and 32 in 2014; finally, the participation on MB was of 24 operators in 2012 and 2013, and 28 in 2014. For a detailed investigation on market power and bidding strategies on MGP see [1] and [2]. During our sample period the Italian MGP registered a downward trend of the PUN. In year 2013 the average PUN value was 66,99€/MWh with a decrease of $16,6 \%$ with respect to the previous year. Data for 2014 confirm this result. The reduction was more significant in peak hours where the average PUN was $€ 70,97 \%(-17,7 \%$ with respect to 2012). More generally, the tendency of the last years was to reduce the difference between peak and offpeak prices. The same trend of price reduction is observed for the four sessions of the intra-day market. The lowest average price was $61,8 € / \mathrm{MWh}$ in MI2 whereas the highest average price was $71,11 € / \mathrm{MWh}$ in $\mathrm{MI}^{3}$. The dynamics of prices in the spot market sessions considered had a peculiar trend if compared to the one realized in the previous years. We notice that for the whole sample period buying prices registered in MI1 and MI2 were always below MGP price whereas average prices formed on MI3 and MI4 were always higher. For all sample years, the dynamics of prices on the MI sessions were correlated with the one of the PUN. It is worth pointing out that the highest prices of the MI3 and MI4 refer to a small number of hours of the day (the last 12 on the former and the last 8 on the latter), in which the contribution of thermal sources on the MGP is higher. Furthermore, as in previous years, during 2013 prices in the four sessions of the MI were constantly below the PUN calculated in the same hours and the phenomenon was increasingly evident in the sessions closer to the time of physical energy delivery.

\section{RES PENETRATION IN ITALY}

The Italian electricity generation has undergone significant changes in the last years. On one hand, the worldwide economic crisis hit aggregate demand and industrial production and, as a consequence, even the electricity demand was severely reduced. On the other hand, policies aimed at accomplishing the EU 20-20-20 target resulted in an effective support for new generation capacity based on renewables. The result of these very generous subsidy schemes, accompanied

\footnotetext{
${ }^{2}$ MSD1 opens at 15.10 and closes at 16.40 on day $T-1$, whereas MSD2 an MSD3 operate on day $T$ but the trading refers to offer/bids submitted on the MSD1. The MB market opens on day $T$ and it is organized in 5 sessions all opening at 23.00 on day $T-1$ and closing one hour and a half before the first hour that may be negotiated.

${ }^{3}$ The above analysis has been conducted on the basis of a concise indicator of the national average value of the MI prices, which is comparable with the PUN. Nonetheless, the result does not change when the zonal prices of the four sessions of the MI are considered.
}

by a preferential treatment of RES production in the dayahead market, produced a reshape of the aggregate supply function, pushing gas fired plant, and CCGT technology in particular, at the far borders of the market. More precisely, from year 2010 until the end of 2013 the amount of electricity produced by CCGT plants fell by $38 \%$ ( $-27.7 \%$ if we consider production from all conventional sources). In the same period the generation from RES grew from 59.5 TWh to 91.4 TWh $(+53.6 \%)$, with a stable share of hydro production which is mainly concentrated in the North zone. Among renewables, wind and solar registered the most relevant result with an increase of respectively $+151 \%$ and $+304 \%$. In 2013 , Italy was the third largest (second largest in the EU) country for PV capacity installed after Germany and China. Very large national supporting schemes eased the advent of new wind and solar capacity into the system. Solar production has been supported mainly by the Conto Energia ${ }^{4}$ which is a feed-intariff recognized for 20 years to new plants. Wind production can take advantage of the Green Certificates scheme. All RES can opt for the direct selling of the excess electricity produced thanks to the $\mathrm{GSE}^{5}$ intermediation that bid the quantity into the MGP. The electricity sold is remunerated at the equilibrium price (or at a minimum price level fixed by the Italian regulator for gas and electricity, AEEG). The most updated information released by the GSE gives an impressive picture of the whole Italian incentive program, with a total of more than 475 thousand plants receiving the support at a cost of over $6 €$ billion. The precise dynamics of RES generation is provided by Figure 1 where the yearly electricity amounts (in GWh) generated by hydro, wind and solar are depicted since 2005 (data for 2014 is provisional). In the analysis we consider the last three years, where RES penetration is increasingly relevant. Indeed, GSE submitted $12.97 \%$ of total bids on MGP in $2012,11.71 \%$ in 2013 , and $8.88 \%$ in 2014 (with total amounts of 111.3 TWh in 2012, 107.1 TWh in 2013, and 100.6 TWh in 2014); the decreasing trend follows reductions in actual load, as consequence of financial crisis. To complete the picture, in 2013 the largest concentration of photovoltaic installations with a level of $54 \%$ was in North, whereas there was only a $29 \%$ in South ${ }^{6}$. On the contrary, at the end of 2012, the largest values of wind generation have been observed in Puglia with 3238 GWh (hence in Southern zone), and in Sicily with 2996 GWh; over a total wind generation of 13407 GWh. Therefore, we are going to consider a restricted set of zones: North, South and Sicily. Detailed RES generations (in GWh) have been reported in Table I for the 3 considered zones (data has been collected from Terna).

\section{Methodology}

We propose a modified version of Skytte's (1999) model to understand the relationship between prices determined on spot and regulation markets accounting for the features of

\footnotetext{
${ }^{4}$ The Conto Energia has been introduced in 2005 and subsequently modified until the last Decree of July, 5th 2012

${ }^{5}$ Gestore dei Servizi elettrici, the Italian publicly owned company

${ }^{6}$ Source: GSE, 2013, Statistical Report on Photovoltaic, page 13 (in Italian).
} 


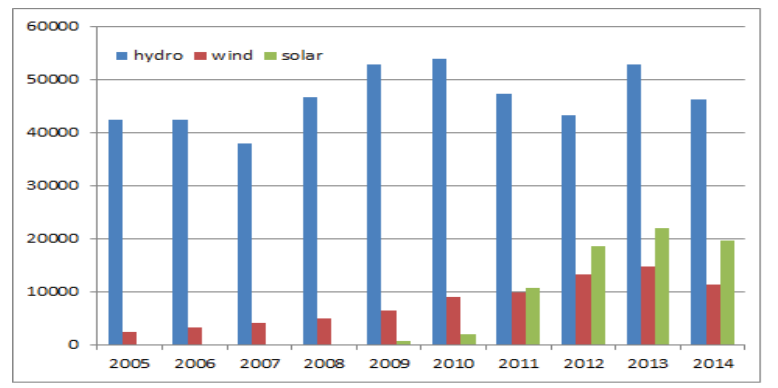

Fig. 1. RES electricity generation in Italy - Source data: ENTSO-E

TABLE I

TOTAL Amounts OF RES-E GENERATION (GWH)

\begin{tabular}{r|r|rrr}
\hline \hline Zone & Year & Hydro & Wind & Solar \\
\hline North & 2012 & 19919 & 123 & 6351 \\
& 2013 & 21105 & 160 & 7097 \\
& 2014 & 25733 & 157 & 8025 \\
\hline South & 2012 & 637 & 6921 & 3835 \\
& 2013 & 794 & 6307 & 3997 \\
& 2014 & 797 & 7586 & 4336 \\
\hline Sicily & 2012 & 82 & 2959 & 1257 \\
& 2013 & 76 & 2658 & 1441 \\
& 2014 & 79 & 3076 & 1703 \\
\hline \hline
\end{tabular}

Italian data, as further explained later. The analysis of Skytte (1999) is limited to a situation in which a spot market is followed by a regulation market whereas in the Italian case the time structure of the power exchange is more complex as we observe overlapping market sessions of intra-day and real time markets where previous buying-selling positions can be updated. Our analysis takes into account these relationships considering the whole quantity exchanged and aggregated price levels, as explained below.

The regulating power markets play an important role in controlling the balance between supply and demand. Indeed, if less power is delivered (or if an excess demand has occurred), then the suppliers have to pay for up-regulating power in order to be able to fulfill the agreements on the spot market, whereas other suppliers get paid to deliver the lack of supply (or, equivalently, some buyers are paid to reduce their demand). On the contrary, if there exists an excess of supply (or less power is used than agreed), then the down-regulation takes place to ensure the right balance into the system. According to Skytte's expectations: 1) the regulating power price should follow the spot price; 2) the difference between the spot and regulating power prices depends on the amount of regulation; 3 ) the regulating power prices may behave differently to up- or down-regulation; 4) as well as the spot prices can be affected differently. According to these assumptions, the model can be formulated as follows

$$
\begin{aligned}
P_{t} & =\alpha S_{t-1} \\
& +I_{Q_{t-1}<D_{t}}\left[\beta S_{t-1}+\gamma\left(Q_{t-1}-D_{t}\right)+\eta\right] \\
& +I_{Q_{t-1}>D_{t}}\left[\beta^{\prime} S_{t-1}+\gamma^{\prime}\left(Q_{t-1}-D_{t}\right)+\eta^{\prime}\right]
\end{aligned}
$$

where $P_{t}$ is the regulation price, $S_{t-1}$ is the spot price determined on the day-ahead market, and $Q_{t-1}$ is the awarded quantity to be sold on the spot market; whereas $D_{t}$ is the actual delivery. Considering the closing times of all market sessions, $S_{t-1}$ and $Q_{t-1}$ are known because the MGP market closes before the beginning of the regulating power markets. The only unknown variable on day T-1 is therefore the actual delivery on day $\mathrm{T}$, that is $D_{t}$. The difference $\left(Q_{t-1}-D_{t}\right)=Q R_{t}$ is the regulating power, which can be positive or negative: there is an excess demand for power when $Q_{t-1}<D_{t}$ (when some producers have delivered less than promised on the spot market; or demand was higher than expected), and the indicator function $I$ is equal to one and zero otherwise (later it will be represented in short notation as $I^{-}$); there is an excess supply when $Q_{t-1}>D_{t}$, and $I$ varies accordingly (in this case, it will be indicated as $I^{+}$). These indicator functions ${ }^{7}$ are included to capture the oscillations in regulating power prices for both the up- or down-regulation. Moreover, the regulating power price equals the spot price if there is no need for regulation. The coefficients $\gamma$ and $\gamma^{\prime}$ represent the marginal regulating power prices per unit of regulated power; whereas the other coefficients, $\beta$ and $\eta$ as well as $\beta^{\prime}$ and $\eta^{\prime}$, are independent of the amount of regulation and are used to determine the premium of readiness paid to the suppliers of regulation services, given their availability to ensure the system balance and their ability to react with a short notice (in terms of minutes, compared instead to the notice of hours occurring into the spot market). It is natural that these compensations depend on the spot price levels and that their amounts are different across the situations of excess demand or excess supply, formally

$$
\begin{gathered}
P R_{t}^{-}=I_{Q_{t-1}<D_{t}}\left[\beta S_{t-1}+\eta\right] \text { and } \\
P R_{t}^{+}=I_{Q_{t-1}>D_{t}}\left[\beta^{\prime} S_{t-1}+\eta^{\prime}\right] .
\end{gathered}
$$

\section{Data And Preliminary Analysis}

All auctions data has been collected from GME and aggregated on yearly basis to identify trends and structural market changes. We indeed focus on the last years from January 2012 to December 2014. This information set refers to all offers to "buy or sell" electricity, hence prices and quantities are provided by individual operators' units. However, we have decided to consider only the production units (hence keeping production, selling and virtual power plants). Then, we have firstly selected the bids to "sell" electricity into the system; secondly, we have kept only the bids "accepted" by the system operators (GME or Terna). Thirdly, on the balancing market, we have additionally kept only the bids not revoked ${ }^{8}$. GME also provided the spot prices (zonal and PUN prices), whereas actual loads have been collected from Terna. Considering our decision of considering North, South and Sicily from the point of view of RES generation, we are

\footnotetext{
${ }^{7}$ They are superfluous if the coefficients in (2) and (3) are estimated to be statistically identical.

${ }^{8} \mathrm{Bids}$ on the balancing market, $\mathrm{MB}$, can be of the following type: revoked on $\mathrm{MB}$ of those bids accepted instead on MSD; not revoked, and (of) netting.
} 
even more confident about this choice since North is also the zone with the highest number of submitted auctions/bids. This information (not reported for lack of space) indirectly gives an indication about the percentage of markets participation in terms of traded $\operatorname{load}^{9}$. Furthermore, we have decided to consider hours 3,11, 13 and 15 firstly because they represent respectively the global minimum, the global maximum, the local minimum and the local maximum of the intra-daily dynamics ${ }^{10}$ of actual load; and secondly because they cover the highest wind and solar generation (GSE, 2013). Given that the data actually refers to two types of regulatory markets (one set for MGP and MI, managed by GME; and the other one for MSD and MB, managed by Terna), we have decided to consider the awarded quantities and prices on MSD, MB and MI markets as the actual markets where the real-time regulation occurs. To this aim, we have identified the amount of regulation, $Q R_{t}$, as the difference between the amount awarded on the spot market, $Q_{t-1}$, and the actual load, $D_{t}$, recordered by Terna; even if these amounts may include selfconsumption. The "spot" prices $S_{t}$ are those awarded on the MGP market (and correspond to the zonal prices); whereas the price of regulating power, $P_{t}$, is computed as an average of prices realized on the adjustment markets weighted by awarded quantities, hence accounting for the pay-as-bid mechanism where allowed. From a preliminary investigation, we document a persistent situation of excess demand in North, and so indicating that the quantity sold on the spot market is always less than actual delivery for all years; on the contrary, in South and Sicily we observe both up- and down-regulation, as depicted in Figure (2). For this reason, we have compared total awarded quantities on MGP in two different years: 2008, when RES generation was limited and the market was not affected by the financial crisis; and 2014, which is the last year of our investigated sample characterized by high RES penetration. Figures reported in Table (II) confirm the decreasing trend of sold quantities on MGP market, hence with corresponding increasing amounts on the balancing markets through years as consequence of increasing stochastic intermittent generation. However, we are unable to compute the regulation power since actual load is available on zonal basis only from 2010.

\section{EMPIRICAL RESULTS}

We estimate eq. (1) and (2), or eq. (1) and (3) to avoid multicollinearity; and this is the reason why we see it as a modified version of Skytte's model, (he indeed estimated eq.1-2-3 simultaneously). According to results ${ }^{11}$ reported in

\footnotetext{
${ }^{9}$ Looking at the size of each market sessions in terms of the total load, we see for instance that $83 \%$ of total load was traded in MGP, against 7\%, 3\%, $5 \%$ and $2 \%$ traded respectively on MSD, MB, MI1, and MI2 at hour 3 in zone North; whereas at the same hour in South, 94\% was traded on MGP, against a $2 \%$ traded on MSD, MI 1 and MI2. A different picture is found in Sicily, where $55 \%$ of total trade was negotiated on MGP, a 34\% was traded on MSD, and 7\%, 3\% and finally $1 \%$ on MB, MI1 and MI2 respectively. And similarly for other hours.

${ }^{10}$ Intra-daily profiles for actual load, wind and solar generation are not included in the paper for lack of space, but they are available on request.
}

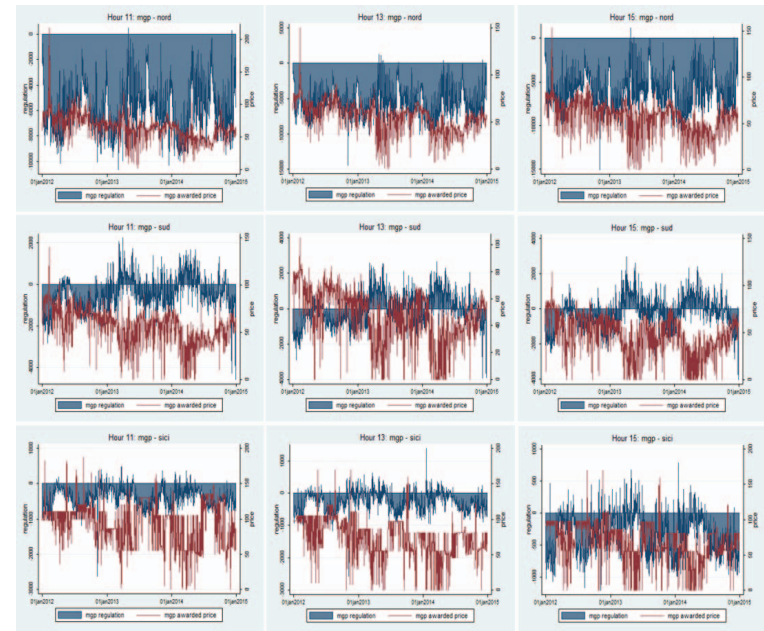

Fig. 2. MGP regulation and awarded prices on North (top row), South (middle) and Sicily (bottom); for hours 11 (first column), 13 (second) and 15 (third)

TABLE II

Average, Minimum and Maximum (CUMUlative) AWARded SOld QUANTITIES (IN MW) IN NORTH FOR SELECTED HOURS AND YEARS

\begin{tabular}{cccc}
\hline \hline & Average & Min & Max \\
\hline \multicolumn{4}{c}{ Hour 3 } \\
\hline $\mathbf{2 0 0 8}$ & 12460 & 7666 & 17979 \\
$\mathbf{2 0 1 4}$ & 8811 & 5934 & 12318 \\
\hline \multicolumn{4}{c}{ Hour 11 } \\
\hline $\mathbf{2 0 0 8}$ & 20189 & 8630 & 27978 \\
$\mathbf{2 0 1 4}$ & 15349 & 8527 & 21640 \\
\hline \multicolumn{4}{c}{ Hour 13 } \\
\hline $\mathbf{2 0 0 8}$ & 18954 & 8600 & 26986 \\
$\mathbf{2 0 1 4}$ & 14014 & 8374 & 19385 \\
\hline \multicolumn{4}{c}{ Hour 15 } \\
\hline $\mathbf{2 0 0 8}$ & 18971 & 8201 & 28316 \\
$\mathbf{2 0 1 4}$ & 14108 & 7609 & 19830 \\
\hline \hline
\end{tabular}

Table (III), we can make the following comments. Firstly, the regulation price is always positively related to spot prices in all considered zones and hours, and in both cases of up- and down-regulation with different magnitudes ${ }^{12}$. Secondly, the global effects of spot prices on regulation prices depend on the status of excess demand or excess supply; in details: if

\footnotetext{
${ }^{11}$ Similar results can be obtained by simply performing regressions on subsamples of excess demand or supply only, but obtaining the total marginal effect of spot prices on regulation prices without disentangling over the status effect. Let us recall that over a sample of 1096 observations, we find only 7 days of excess supply for hour 3 in North (143 in South, and 121 in Sicily); 2 days for hour 11 in North (whereas 303 in South and 76 in Sicily), 7 days for hour 13 in North (487 in South, and 205 in Sicily); and 4 days for hour 15 in North (397 in South, and 176 in Sicily); finally, only 5 days for hour 18 in North (78 in South, and 24 in Sicily). The augmented Dickey-Fuller test performed (with a constant and trend) on both spot and regulation prices confirmed that the processes are stationary.

${ }^{12}$ We have generally observed the under estimation of spot quantities, specially in North; and then, we suspect that "bidding systematically low quantities" on MGP may be influenced by the introduction of increasing RES generation.
} 
there is excess demand ${ }^{13}$ in North (cases of $I^{-}$), the effects of spot prices on regulation prices are $0.145 € / \mathrm{MWh}$ in hour 3 (this amount is obtained by adding the estimated coefficients, $2.895-2.750$ ), 0.093 in hour 13 , and 0.045 in hour 15. If we move in South, we observe that up- or down-regulation is never found significant in terms of prices and quantities; and indeed, we have observed bids on MB only for hours 20 to 24 . In Sicily, spot prices affect regulation prices almost similarly in case of excess demand (or excess of supply, in brackets): for $0.097 € / \mathrm{MWh}(0.016)$ in hour 3, 0.297 (0.021) in hour 13, and $0.238(0.212)$ in hour 15 . Thirdly, the amount of regulation plays a very low effect on regulation prices since it ranges among $0.1 \%$ and $2.8 \%$, when significant. Finally, the constants $\eta$ and $\eta^{\prime}$ are significant and very large, hence affecting the premia of readiness paid to the suppliers of regulation services independently from the amount of regulation. These premia have been estimated and represented in Figure 3.

TABLE III

Model Estimates

\begin{tabular}{|c|c|}
\hline & Hour 3 \\
\hline North & $\begin{array}{l}P_{t}=2.895^{* * *} S_{t-1}+I^{-}\left[-2.750^{* * *} S_{t-1}+0.001^{* * *} Q R_{t}+140.603^{* * *}\right] \\
P_{t}=2.768^{* * *} S_{t-1}+I^{+}\left[-2.840 S_{t-1}+0.034 Q R_{t}+133.437^{*}\right]\end{array}$ \\
\hline South & $\begin{array}{l}P_{t}=1.103^{* * *} S_{t-1}+I^{-}\left[0.009 S_{t-1}+0.001 Q R_{t}-1.939\right] \\
P_{t}=1.046^{* * *} S_{t-1}+I^{+}\left[0.110 S_{t-1}-0.001 Q R_{t}-1.230\right]\end{array}$ \\
\hline \multirow[t]{2}{*}{ Sicily } & $\begin{array}{l}P_{t}=3.165^{* * *} S_{t-1}+I^{-}\left[-3.068^{* * *} S_{t-1}-0.005 Q R_{t}+128.535^{* * *}\right] \\
P_{t}=2.024^{* * *} S_{t-1}+I^{+}\left[-2.008^{* * *} S_{t-1}+0.008 Q R_{t}+137.913^{* * *}\right]\end{array}$ \\
\hline & Hour 13 \\
\hline North & $\begin{array}{l}P_{t}=2.760^{* * *} S_{t-1}+I^{-}\left[-2.667^{* * *} S_{t-1}+0.003^{* * *} Q R_{t}+148.957^{* * *}\right] \\
P_{t}=2.285^{* * *} S_{t-1}+I^{+}\left[-3.824^{* * *} S_{t-1}-0.034 Q R_{t}+204.348^{* * *}\right]\end{array}$ \\
\hline South & $\begin{array}{l}P_{t}=1.131^{* * *} S_{t-1}+I^{-}\left[-0.115 S_{t-1}+0.000 Q R_{t}+3.369\right] \\
P_{t}=1.065^{* * *} S_{t-1}+I^{+}\left[0.018 S_{t-1}+0.003 Q R_{t}+0.082\right]\end{array}$ \\
\hline \multirow[t]{2}{*}{ Sicily } & $\begin{array}{l}P_{t}=2.413^{* * *} S_{t-1}+I^{-}\left[-2.116^{* * *} S_{t-1}+0.021^{* * *} Q R_{t}+126.540^{* * *}\right] \\
P_{t}=1.660^{* * *} S_{t-1}+I^{+}\left[-1.639^{* * *} S_{t-1}+0.013 Q R_{t}+143.722^{* * *}\right]\end{array}$ \\
\hline & Hour 15 \\
\hline North & $\begin{array}{l}P_{t}=3.198^{* * *} S_{t-1}+I^{-}\left[-3.153^{* * *} S_{t-1}+0.003^{* * *} Q R_{t}+154.588^{* * *}\right] \\
P_{t}=2.205^{* * *} S_{t-1}+I^{+}\left[-3.193^{* *} S_{t-1}-0.019 Q R_{t}+184.610^{* * *}\right]\end{array}$ \\
\hline South & $\begin{array}{l}P_{t}=1.138^{* * *} S_{t-1}+I^{-}\left[0.007 S_{t-1}+0.001 Q R_{t}-4.958\right] \\
P_{t}=1.047^{* * *} S_{t-1}+I^{+}\left[-0.049 S_{t-1}+0.004^{*} Q R_{t}+3.458\right]\end{array}$ \\
\hline Sicily & $\begin{array}{l}P_{t}=2.851^{* * *} S_{t-1}+I^{-}\left[-2.613^{* * *} S_{t-1}+0.028^{* * *} Q R_{t}+136.016^{* * *}\right] \\
P_{t}=1.745^{* * *} S_{t-1}+I^{+}\left[-1.533^{* * *} S_{t-1}+0.024 Q R_{t}+140.414^{* * *}\right]\end{array}$ \\
\hline & $Q_{t-1}<D_{t}$ and $I^{+}=I_{Q_{t-1}>D_{t}}$ \\
\hline
\end{tabular}

\section{COMments And CONCLUSions}

Our results confirm Skytte's first expectation on regulating power prices following spot prices, and in some cases, being the former ones amplified by two or three times the latter ones. Contrary to his second expectation, we generally observe that the amount of regulation does not evidently affect regulating power prices, even if they actually behave differently to upand down-regulation. In addition, we find an important empirical evidence on premia for readiness. It is very interesting to note that these premia are very large considering the effect of financial crisis, and compared to those found by Skytte in 1999. This may indicate that operators are finding into the regulation markets higher profits that compensate their lower

\footnotetext{
${ }^{13} \mathrm{We}$ do not compute the total effect in cases of excess supply given that the statistics are based on few - less than 30 - observations.
}

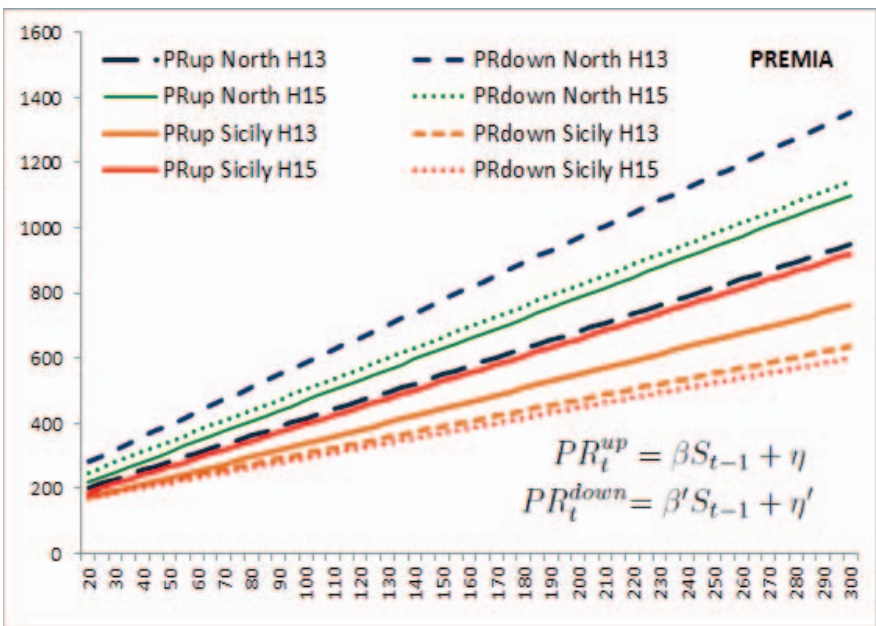

Fig. 3. Estimated Premia for Readiness (in €/MWh) for hours 13 and 15 in North and Sicily

earnings realized on MGP as consequence of the increasing competition. On the contrary, the limited number of market participants acting on the regulation markets gives the opportunity to exercise here the market power no longer executable on the spot market. Therefore, based on this evidence, we can conclude that the need for more balancing services due to the high RES penetration induces highly increasing profits to the generators acting on these adjustment or real-time markets, then Italian consumers' final payments tend to be very high as well. Hence, lowering power prices is not possible by progressive RES generation with this market structure.

\section{ACKNOWLEDGMENT}

The first author thanks the DEMS visiting scholar programme at the University of Milano Bicocca for supporting this research project.

\section{REFERENCES}

[1] Bosco B., Parisio L. and Pelagatti M., (2012), Strategic bidding in vertically integrated power markets with an application to the Italian electricity auctions, Energy Economics, 34, 2046-2057

[2] Bosco B., Parisio L. and Pelagatti M., (2013), Price-capping in partially monopolistic electricity markets with an application to Italy, Energy Policy, 54, 257-266

[3] ENTSO-E, European network of transmission system operators for electricity, www.ent soe.eu

[4] Gianfreda A. and Grossi L.,(2012), Forecasting Italian Electricity Zonal Prices with Exogenous Variables, Energy Economics, 34, 6, 2228-2239

[5] GME, Gestore dei Mercati energetici, www .mercatoelettrico.org

[6] GSE, Gestore dei Servizi, www.gse. it

[7] GSE, (2013), Statistical Report on Photovoltaic, report in Italian

[8] Skytte K., (1999), The regulating power market on the Nordic power exchange Nord Pool: an econometric analysis, Energy Economics, 21, 295-308

[9] TERNA, Italian Transmission System Operator, www.terna.it 